REVISTA DE DERECHO UNED, núm. 1, 2006

\title{
EL LEGADO DE DERECHO DE HABITACIÓN REGULADO EN EL ARTÍCULO 822 DEL CÓDIGO CIVIL ${ }^{1}$
}

\author{
Tomas Noguera Nebot
}

Sumario: I. INTRODUCCIÓN.-II. REFERENCIA A LA LEY 41/2003, DE 18 DE NOVIEMBRE, DE PROTECCIÓN PATRIMONIAL DE LAS PERSONAS CON DISCAPACIDAD Y DE MODIFICACIÓN DEL CÓDIGO CIVIL, DE LA LEY DE ENJUICIAMIENTO CIVIL Y DE LA NORMATIVA TRIBUTARIA CON ESTA FINALIDAD.-III. EL LEGADO DE DERECHO DE HABITACIÓN REGULADO EN EL NUEVO ARTÍCULO 822 DEL CÓDIGO CIVIL.-1. Significado de la expresión "persona con discapacidad».-2. Legitimario.-3. Derecho de Habitación.-4. Donación y Legado como títulos para adquirir un derecho de habitación sobre la vivienda habitual.-5. Respeto a los derechos del cónyuge regulados en los artículos 1.406 y 1.407 del Código Civil.

\section{INTRODUCCIÓN}

La Constitución Española —en su Título Preliminar- establece en el artículo 9.2 que «corresponde a los poderes públicos promover las condiciones para que la libertad y la igualdad del individuo y de los grupos en que se integra sean reales y efectivas; remover los obstáculos que impidan o dificulten su plenitud y facilitar la participa-

1 Por Tomás Noguera Nebot, Profesor de Derecho Civil de la Universidad de Huelva. 
ción de todos los ciudadanos en la vida política, económica, cultural y social». Y dentro de «los principios rectores de la política social y económica» el artículo 49 dispone que «los poderes públicos realizarán una política de previsión, tratamiento, rehabilitación e integración de los disminuidos físicos, sensoriales y psíquicos, a los que prestarán la atención especializada que requieran y los ampararán especialmente para el disfrute de los derechos que este Título (Título I «De los derechos y deberes fundamentales») otorga a todos los ciudadanos».

Son muchos los mecanismos que, en cumplimiento del mandato que a los poderes públicos da el artículo 49, tratan de responder a la especial situación de las personas con discapacidad, ordenando los medios necesarios para que la minusvalía que padecen no les impida el disfrute de los derechos que a todos los ciudadanos reconocen la Constitución y las leyes.

En ese sentido podemos destacar la Ley 41/2003, de 18 de noviembre, de protección patrimonial de la personas con discapacidad y de modificación del Código Civil, de la Ley de Enjuiciamiento Civil y de la Normativa Tributaria con esta finalidad, que fue publicada en el B.O.E. de 19 de noviembre de 2.003 y que entró en vigor al día siguiente.

Dicha Ley fue aprobada en un momento de especial sensibilización de la sociedad y de los poderes públicos hacia las personas con discapacidad: el año 2003 fue declarado «Año Europeo de las personas con discapacidad».

\section{REFERENCIA A LA LEY 41/2003, DE 18 DE NOVIEMBRE, DE PROTECCIÓN PATRIMONIAL DE LAS PERSONAS CON DISCAPACIDAD Y DE MODIFICACIÓN DEL CÓDIGO CIVIL, DE LA LEY DE ENJUICIAMIENTO CIVIL Y DE LA NORMATIVA TRIBUTARIA CON ESTA FINALIDAD}

Como señala su Exposición de Motivos, la ley tiene por objeto regular nuevos mecanismos de protección de las personas con discapacidad, centrados en un aspecto esencial de esta protección, cual es el patrimonial. Uno de los elementos que más repercuten en el bienestar de dichas personas es la existencia de medios económicos a su disposición, suficientes para atender las específicas necesidades vitales de los mismos. En buena medida, dichos medios son proporcionados por los poderes públicos, sea directamente, a través de servicios públicos dirigidos a estas personas, sea indirectamente a través 
de distintos instrumentos como beneficios fiscales o subvenciones específicas.

El objeto inmediato de esta ley -destaca la Exposición de Motivos- es la regulación de una masa patrimonial, el patrimonio especialmente protegido de las personas con discapacidad, la cual queda inmediata y directamente vinculada a la satisfacción de las necesidades vitales de una persona con discapacidad, favoreciendo la constitución de este patrimonio y la aportación a título gratuito de bienes y derechos a la misma. Los bienes y derechos que forman este patrimonio, que no tiene personalidad jurídica propia se aíslan del resto del patrimonio personal de su titular-beneficiario, sometiéndolos a un régimen de administración y supervisión específico.

La regulación contenida en la ley se entiende sin perjuicio de las disposiciones que pudieran haberse aprobado en las comunidades autónomas con derecho civil propio, las cuales tienen aplicación preferente de acuerdo con el artículo $149.1 .8^{\text {a }}$ de la Constitución española y los diferentes Estatutos de autonomía, siéndoles de aplicación esta ley con carácter supletorio conforme a la regla general contenida en el artículo 13.2 del Código Civil.

La ley regula la necesaria supervisión de la administración del patrimonio protegido de las personas con discapacidad, articulándola de varias formas; por una parte, el constituyente del patrimonio puede determinar las reglas para efectuarla, pero, por otra se establece una supervisión institucional a cargo del Ministerio Fiscal.

Por otro lado la ley crea la Comisión de Protección Patrimonial de las Personas con Discapacidad, como órgano externo de apoyo, auxilio y asesoramiento del Ministerio Fiscal en el ejercicio de sus funciones. En el B.O.E. de 6 de febrero de 2004 se publicó el «Real Decreto $177 / 2.004$, de 30 de enero, por el que se determina la composición, funcionamiento y funciones de la Comisión de protección patrimonial de las personas con discapacidad». Este Real Decreto entró en vigor el 7 de febrero de 2004.

El contenido de la Ley 41/2003 -según destaca su Exposición de Motivos- no acaba en la regulación del patrimonio protegido de las personas con discapacidad, sino que además se incorporan distintas modificaciones de la legislación vigente que tratan de mejorar la protección patrimonial de estas personas, aumentando las posibilidades jurídicas de afectar medios económicos a la satisfacción de las necesidades de estas personas o que, en general, mejoran el tratamiento jurídico de las personas con discapacidad. Hay que destacar 
que estas modificaciones se han realizado siguiendo las pautas aconsejadas por la Comisión General de Codificación.

A continuación vamos a hacer una breve referencia a las distintas modificaciones legislativas introducidas por la Ley 41/2003. Trás el Capítulo I (artículos 1 a 8 ) referido al «Patrimonio protegido de las personas con discapacidad», el Capítulo II (artículos 9 a 14) se refiere a las "Modificaciones del Código Civil y de la Ley de Enjuiciamiento Civil» y el Capítulo III (artículos 15 a 17) a la "Modificación de la normativa tributaria».

El artículo 9 de la Ley modifica el Código Civil en materia de autotutela y afecta a los artículos 223, 234 y 239.

El artículo 10 de la Ley modifica el Código Civil en materia de régimen sucesorio y afecta a los artículos 756, 782, 808, 813, 821, 822 (que va a ser objeto de nuestro comentario, posteriormente), 831 y 1.041 .

El artículo 11 de la Ley modifica el Código Civil en materia de mandato y afecta al artículo 1.732 .

El artículo 12 de la Ley crea un nuevo capítulo II del título XII del libro IV del Código Civil, bajo la rúbrica "Del contrato de alimentos», que engloba los artículos 1.791 a 1.797, a los que da nueva redacción.

El artículo 13 de la Ley incorpora una nueva disposición adicional en el Código Civil: la disposición adicional cuarta.

El artículo 14 de la Ley modifica la Ley 1/2000, de 7 de enero, de Enjuiciamiento Civil en materia de procesos sobre la capacidad de las personas y afecta al artículo 757.

El artículo 15 de la Ley modifica la Ley 40/1998, de 9 de diciembre, del Impuesto sobre la Renta de las Personas Físicas y otras Normas Tributarias y afecta a los artículos $15,16,46,86$ y a la disposición adicional decimocuarta. También añade un artículo 47 sexies referido a las «Reducciones por aportaciones a patrimonios protegidos de las personas discapacitadas».

El artículo 16 de la Ley modifica la Ley 43/1995, de 27 de diciembre, del Impuesto sobre Sociedades y afecta al artículo 36 quáter.

El artículo 17 de la Ley modifica el Real Decreto Legislativo 1/1993, de 24 de septiembre, por el que se aprueba el texto refundido de la Ley del Impuesto sobre Transmisiones Patrimoniales y Actos Jurídicos Documentados y afecta al artículo 45.I. 
Por último la Ley 41/2.003 cuenta con dos disposiciones adicionales y tres disposiciones finales.

\section{EL LEGADO DE DERECHO DE HABITACIÓN REGULADO EN EL NUEVO ARTÍCULO 822 DEL CÓDIGO CIVIL}

El nuevo artículo 822 del Código Civil establece que «La donación o legado de un derecho de habitación sobre la vivienda habitual que su titular haga a favor de un legitimario persona con discapacidad, no se computará para el cálculo de las legítimas si en el momento del fallecimiento ambos estuvieren conviviendo en ella.

Este derecho de habitación se atribuirá por ministerio de la ley en las mismas condiciones al legitimario discapacitado que lo necesite y que estuviera conviviendo con el fallecido, a menos que el testador hubiera dispuesto otra cosa o lo hubiera excluido expresamente, pero su titular no podrá impedir que continúen conviviendo los demás legitimarios mientras lo necesiten.

El derecho a que se refieren los dos párrafos anteriores será intransmisible.

Lo dispuesto en los dos primeros párrafos no impedirá la atribución al cónyuge de los derechos regulados en los artículos 1.406 y 1.407 de este Código, que coexistirán con el de habitación».

En primer lugar hay que destacar que el contenido del artículo 822 es completamente nuevo. Asimismo hay que precisar que la disposición normativa ubicada en el anterior artículo 822 ha pasado - con nueva redacción - a constituir un nuevo párrafo tercero del artículo 821; cambio introducido por el artículo 10 de la Ley 41/2003.

\section{SIGNIFICADO DE LA EXPRESIÓN «PERSONA CON DISCAPACIDAD»}

Hay que precisar cual es el significado de la expresión persona con discapacidad que utiliza el artículo 822. Para ello debemos acudir a la nueva disposición adicional cuarta del Código Civil (añadida por el artículo 13 de la Ley 41/2.003) que establece: «La referencia que a personas con discapacidad se realiza en los artículos 756, 822 y 1.041, se entenderá hecha al concepto definido en la Ley de protección patrimonial de las personas con discapacidad y de Modificación del Código Civil, de la Ley de Enjuiciamiento Civil y de la Normativa Tributaria con esta finalidad». 
Y conforme al artículo 2.2 de la citada Ley «únicamente tendrán la consideración de personas con discapacidad:

a) Las afectadas por una minusvalía psíquica igual o superior al 33 por ciento.

b) Las afectadas por una minusvalía física o sensorial igual o superior al 65 por ciento».

Por su parte el párrafo tercero del mismo artículo 2 nos indica cómo se acredita el grado de minusvalía, a saber «mediante certificado expedido conforme a lo establecido reglamentariamente o por resolución judicial firme».

Por tanto, y como la propia Exposición de Motivos de la Ley explica al referirse a los beneficiarios de patrimonios protegidos, en las personas con discapacidad pueden concurrir o no las causas de incapacitación judicial contempladas en el artículo 200 del Código Civil y, concurriendo, tales personas pueden haber sido o no judicialmente incapacitadas. Es decir, para tener la consideración de "persona con discapacidad» no es imprescindible estar judicialmente incapacitado; sólo es necesario estar afectado por los grados de minusvalía señalados en el artículo 2.2; y el grado de minusvalía se puede acreditar - como hemos dicho antes- «mediante certificado expedido conforme a lo establecido reglamentariamente».

\section{LEGITIMARIO}

Para ser donatario o legatario de un derecho de habitación sobre la vivienda habitual, según el artículo 822 , además de "persona con discapacidad" hay que ser legitimario. Quiénes son legitimarios nos lo dice el artículo 807 del Código Civil:

"1. Los hijos y descendientes respecto de los padres y ascendientes.

2. ${ }^{\circ}$ A falta de los anteriores, los padres y ascendientes respecto de sus hijos y descendientes.

3. El viudo o viuda en la forma y medida que establece éste código».

Por tanto, si el legitimario (heredero) se beneficia del derecho de habitación por la vía del legado nos encontramos ante la figura del prelegado. 
Además, para que la donación o legado de un derecho de habitación sobre la vivienda habitual no se compute para el cálculo de la legítima es necesario que el "legitimario persona con discapacidad» esté conviviendo con el titular de la vivienda - en la misma- en el momento del fallecimiento de éste.

Es plausible la norma por establecer el beneficio de no computar para el cálculo de la legítima la donación o legado del derecho de habitación a favor de las personas con discapacidad; y sobre todo por facilitar la posibilidad de que estas personas puedan disfrutar de una vivienda, concretamente de la «facultad de ocupar en casa ajena las piezas necesarias para sí y para las personas de su familia" (Derecho de habitación según el artículo 524.2 del Código Civil).

\section{DERECHO DE HABITACIÓN}

El derecho de habitación es regulado por el Código Civil, junto con el derecho de uso, en los artículos 523 a 529. Ambos derechos se pueden considerar como un derivado o apéndice del derecho de usufructo.

Según el artículo 524 del Código Civil «el uso da derecho a percibir de los frutos de la cosa ajena los que basten a las necesidades del usuario y de su familia, aunque ésta se aumente». En al misma línea dispone el artículo 526 que «el que tuviere el uso de un rebaño o piara de ganado, podrá aprovecharse de las crías, leche y lana en cuanto baste para su consumo y el de su familia, así como también del estiércol necesario para el abono de las tierras que cultive». Por tanto el usuario disfruta para satisfacer una necesidad y no puede obtener beneficios superiores a la satisfacción de la misma. Éste es el límite del derecho de uso.

Según los profesores DíEz-Picazo y GuLLóN ${ }^{2}$ el derecho real de habitación es una forma de derecho de uso caracterizado por el objeto sobre el que recae.

Por su parte el profesor Clemente Meoro 3 indica que del artículo 524.2 del C.C. se obtienen como características del derecho de habitación: $\left.1 .^{a}\right)$ recaer sobre un objeto determinado, una casa ajena, y

2 Sistema de Derecho Civil, volumen III, Ed. Tecnos, Madrid, 5. ${ }^{\text {a }}$ ed., 1990, (4. ${ }^{\text {a }}$ reimpresión, 1995) pg. 435.

3 En Derechos Reales y Derecho Inmobiliario Registral, BLASCo Gasco y otros, Ed. Tirant lo Blanch, Valencia, 1994, pg. 501. 
para fin determinado, vivienda; $2{ }^{a}$ ) no conceder al titular un derecho sobre los frutos. También señala el citado profesor que no es lo mismo un derecho de uso - tal y como lo tipifica el Código Civil-que recaiga sobre una casa que un derecho de habitación. El usuario de una casa podrá usar la casa para vivienda o para otros fines, mientras que el titular del derecho de habitación sólo puede tenerla de vivienda propia y de su familia.

En cuanto al régimen jurídico de los derechos de uso y habitación el artículo 523 del C.C. establece que «las facultades y obligaciones del usuario y del que tiene derecho de habitación se regularán por el título constitutivo de estos derechos; $y$, en su defecto por las disposiciones siguientes». Y el artículo 528 señala que «las disposiciones establecidas para el usufructo son aplicables a los derechos de uso y habitación, en cuanto no de opongan a lo ordenado en el presente capítulo». Por tanto esos derechos se regirán: en primer lugar, por lo dispuesto en su título de constitución; en segundo lugar, por lo dispuesto en los artículos 523 a 529 del C.C. y, subsidiariamente por las disposiciones establecidas para el usufructo, en la medida en que sean aplicables.

En cuanto a las obligaciones de los titulares de los derechos de uso y de habitación el artículo 527 del C.C. dice «si el usuario consumiera todos los frutos de la cosa ajena, o el que tuviere derecho de habitación ocupara toda la casa, estará obligado a los gastos de cultivo, a los reparos ordinarios de conservación y al pago de las contribuciones, del mismo modo que el usufructuario.

Si sólo percibiera parte de los frutos o habitara parte de la casa, no deberá contribuir con nada, siempre que quede al propietario una parte de frutos o aprovechamiento bastantes para cubrir los gastos y las cargas. Si no fueren bastantes suplirá aquel lo que falte».

El artículo 525 del C.C. indica que «los derechos de uso y habitación no se pueden arrendar ni traspasar a otro por ninguna clase de título». Esto supone una diferencia importante entre estos derechos y el derecho de usufructo. Por otro lado, mientras que el artículo 107.1 de la Ley Hipotecaria permite la hipoteca del derecho de usufructo, el artículo108.3 de la misma ley no permite hipotecar los derechos de uso y habitación.

Según señala CLEMENTE MEORO ${ }^{4}$ la mayor parte de la doctrina entiende que la intransmisibilidad de los derechos de uso y habitación recogida en el artículo 525 del C.C. no es de derecho necesario

\footnotetext{
${ }^{4}$ En Derechos Reales y..., citado, pg. 502
} 
en cuanto que las facultades el del usuario y del que tiene derecho de habitación se regularán en primer lugar por el título constitutivo y, por tanto, éste puede establecer la transmisibilidad. El problema radica más bien en determinar si esos derechos, en cuanto transmisibles, dejan de ser derechos de uso o habitación para convertirse en usufructos de contenido limitado. Es decir, si se aplicarán o no las normas relativas a los derechos de uso y habitación contenidas en el Código Civil, especialmente las relativas a las obligaciones del titular (art. 527) y extinción del derecho (art. 529). Clemente Meoro opina que en cuanto el contenido del derecho esté limitado en el sentido en que lo establecen los artículos 524 y 526 el C.C., aunque sea transmisible, serán aplicables los artículos 523 a 529 del C.C. y, en lo que no se opongan a lo dispuesto en éstos, las disposiciones establecidas para el usufructo.

En el caso concreto del derecho de habitación previsto en los párrafos primero y segundo del artículo 822 del C.C., el párrafo tercero del mismo articulo señala expresamente «el derecho a que se refieren los dos párrafos anteriores será intransmisible». En el supuesto del párrafo segundo, al ser el propio Código el que atribuye el derecho de habitación, no hay duda de su intransmisibilidad. En el supuesto del párrafo primero, la cuestión se podría plantear si el donante o el testador al instituir el derecho de habitación estableciesen que el beneficiario del mismo pudiera transmitirlo. Como el artículo 822 contiene una regulación específica del derecho de habitación, parece que prevalecería la intransmisibilidad prevista en el párrafo tercero sobre lo dispuesto por la persona que instituya el derecho de habitación por donación o por legado.

En cuanto a la extinción de los derechos de uso y habitación el artículo 529 del C.C. señala que dichos derechos «se extinguen por las mismas causas que el usufructo, y además por abuso grave de la cosa y de la habitación». El Código Civil regula la extinción del usufructo en los artículos 513 a 522, estableciendo el primero de ellos que «el usufructo se extingue: $1^{\circ}$. Por muerte del usufructuario. $2^{\circ}$. Por expirar el plazo por el que se constituyó, o cumplirse la condición resolutoria consignada en el título constitutivo. $3^{\circ}$. Por la reunión del usufructo y la propiedad en una misma persona. $4^{\circ}$. Por renuncia del usufructuario. $5^{\circ}$. Por la pérdida total de la cosa objeto del usufructo. $6^{\circ}$. Por la resolución del derecho del constituyente. $7^{\circ}$. Por prescripción». La peculiaridad, pues, de los derechos de uso y habitación es su extinción "por abuso grave de la cosa y de la habitación", lo cual no ocurre en el usufructo. Obsérvese que, para un supuesto similar referido a éste último, el artículo 520 del C.C. establece que «el usufructo no se ex- 
tingue por el mal uso de la cosa usufructuada; pero si el abuso infiriese considerable perjuicio al propietario, podrá éste pedir que se le entregue la cosa, obligándose a pagar anualmente al usufructuario el producto líquido de la misma, después de deducir los gastos y el premio que se le asignare por su administración». De todas formas la Jurisprudencia estableció en Sentencias de 28 noviembre 1.908 y de 30abril 1.910 que la regla - por la que los derechos de uso y habitación se extinguen "por abuso grave de la cosa y de la habitación"- es de interpretación restrictiva, debido a la dureza de la sanción que impone.

Por otro lado, hay que destacar que la persona con discapacidad beneficiaria del derecho de habitación sobre la vivienda habitual puede ser titular de un patrimonio especialmente protegido o no. Si es titular de un patrimonio protegido, el derecho de habitación debe constar como integrante del citado patrimonio en la inscripción que se practique a favor de la persona con discapacidad en el Registro de la Propiedad correspondiente, según el artículo 8.2 de la Ley 41/2.003.

\section{DONACIÓN Y LEGADO COMO TÍTULOS PARA ADQUIRIR UN DERECHO DE HABITACIÓN SOBRE LA VIVIENDA HABITUAL}

El artículo 822 del C.C. se refiere a la donación y al legado como títulos para adquirir un derecho de habitación sobre la vivienda habitual. Vamos a referimos a cada uno de ellos.

La DONACIÓN es, según el profesor LASARTE 5 , «la transmisión voluntaria de una cosa o de un conjunto de ellas que hace una persona, donante, a favor de otra, donatario, sin recibir nada como contraprestación». El Código Civil, en su artículo 618, la define como: «el acto de liberalidad por el cual una persona dispone gratuitamente de una cosa a favor de otra que la acepta».

El Código Civil no califica la donación como contrato, sino como acto, y la regula al tratar «de los diferentes modos de adquirir la propiedad". Sin embargo el carácter contractual de la donación le viene dado por el artículo 630 del C.C. al exigir la aceptación por parte del donatario: «El donatario debe, so pena de nulidad, aceptar la donación por sí, o por medio de persona autorizada con poder especial

5 Principios de Derecho Civil, tomo tercero, 8. ${ }^{2}$ edición, Ed. Marcial Pons, Madrid, 2004, pg. 193. 
para el caso, o con poder general y bastante». Por tanto, el donatario de un derecho de habitación debe aceptarlo, si desea adquirirlo.

Como señala el profesor Lasarte, además de un contrato, la donación es un modo de adquirir que, según se afirma, opera sin necesidad de tradición simultánea o posterior, como establece el artículo 609 del C.C. al decir que «la propiedad y los demás derechos sobre los bienes (entre los que podemos reseñar el derecho de habitación) se adquieren y transmiten... por donación... y por consecuencia de ciertos contrato mediante la tradición». La donación es, por tanto, un contrato en virtud del cual se adquiere directamente el dominio.

Es llamativo que el artículo 822 del C.C. se refiera - junto al legado- a la donación (que es, por principio, un acto realizado inter vivos) como título para transmitir un derecho de habitación sobre la vivienda habitual del titular-donante en vida de éste, ya que si lo que se persigue es que el legitimario discapacitado pueda habitar en la vivienda habitual de aquel, ello se puede conseguir sin necesidad de concederle el citado derecho de habitación, simplemente con el consentimiento del titular; a menos que se quiera formalizar anticipadamente el derecho de habitación. Ya que el titular de la vivienda habitual siempre puede instituir el legado de derecho de habitación en su testamento, lo que habilitaría que el legitimario discapacitado -que ya la habitaba- continuase habitando en la vivienda habitual del testador tras el fallecimiento de éste.

Cabe la posibilidad de que la donación reseñada en el artículo 822.1 del C.C. se pueda identificar con la modalidad prevista en el artículo 620 del mismo texto legal, si así lo ha establecido el donante. Éste último articulo establece que «las donaciones que hayan de producir sus efectos por muerte del donante participan de la naturaleza de las disposiciones de última voluntad, y se regirán por las reglas establecidas en el capitulo de la sucesión testamentaria». Como señala el profesor LASARTE ${ }^{6}$ la referencia a las donaciones mortis causa contenida en este artículo ha provocado un debate doctrinal sobre la admisibilidad o no de una figura que, existente en el Derecho romano, se podría considerar erradicada del Código Civil según la opinión mayoritaria de la doctrina y la jurisprudencia. La interpretación del citado artículo gira acerca de considerar que bajo nuestro actual Derecho positivo las históricamente denominadas donaciones mortis causa han de ser asimiladas a los legados hechos en testamento, de forma tal que - como

\footnotetext{
${ }^{6}$ Principios de Derecho Civil, tomo tercero citado, pg. 195.
} 
señala la jurisprudencia- ha de considerarse que la posposición de los efectos de tales donaciones hasta el fallecimiento del «donante» supone que, en realidad, han de ser consideradas revocables y quedan sin efecto hasta que, tras el fallecimiento del donante, sean objeto de reconocimiento en la pertinente disposición testamentaria. En conclusión, por tanto, en el supuesto de que la donación reseñada en el artículo 822.1 del C.C. se identifique con la modalidad prevista en el artículo 620 del mismo Código, la misma se estaría asimilando al legado hecho en testamento.

En cuanto al LEGADO, hay que partir de la gran dificultad de encontrar un concepto unitario del mismo, dada la inmensa variedad de formas que puede revestir, así como por las distintas funciones económicas que puede desempeñar. Ante esa dificultad, algún sector doctrinal adopta una actitud pasiva: es legado toda atribución patrimonial hereditaria distinta de la institución de heredero. Se trata de un concepto meramente residual, que no soluciona la cuestión. Dadas las múltiples formas que puede revestir el legado, parece que hay que recurrir a formulaciones necesariamente abstractas, que comprendan todas y cada una de las posibles figuras de legado. En dicha línea podemos reseñar el concepto del profesor ALBALADEJo, según el cual el legado es "una disposición mortis causa de bienes, a título particular, en beneficio del legatario y a cargo del patrimonio hereditario"; junto con este concepto, destacado por el profesor LASARTE7, también podemos resaltar el que da éste último, cuando afirma que el legado « es una atribución jurídico-patrimonial que el causante, de forma directa y singular, realiza en el testamento a favor de cualquier persona».

En concreto, el legado al que alude el artículo 822.1 parece que es un legado de un derecho real (derecho de habitación) sobre una cosa específica y determinada (vivienda habitual) propiedad del testador («...derecho de habitación sobre la vivienda habitual que su titular haga...), en el entendido que el vocablo titular que utiliza el citado artículo se identifique con propietario. En relación con éste supuesto el artículo 882.1 del C.C. establece que «cuando el legado es de cosa específica y determinada, propia del testador, el legatario adquiere su propiedad desde que aquel muere, y hace suyos los frutos o rentas pendientes, pero no las rentas devengadas y no satisfechas antes de la muerte.» Y el párrafo segundo añade que «la cosa legada correrá desde el mismo instante a riesgo del legatario, que sufrirá, por

7 Principios de Derecho Civil, tomo séptimo, 3. ${ }^{a}$ ed., Ed. Marcial Pons, Madrid, 2203 , pág. 182. 
tanto, su pérdida o deterioro, como también se aprovechará de su aumento o mejora».

En el supuesto de éste artículo, aunque el legatario es propietario desde la muerte del testador, el artículo 885 le prohíbe ocupar por sí la cosa legada, y dispone que debe pedir su entrega y posesión al heredero o al albacea, cuando éste se halle autorizado para darla. Ello se explica en base a lo dispuesto por el artículo 440.1 del C.C. cuando establece que "la posesión (la llamada posesión civilísima) de los bienes hereditarios se entiende transmitida al heredero sin interrupción y desde el momento de la muerte del causante, en el caso de que llegue a adirse a la herencia».

Las peculiaridades del supuesto previsto en el artículo 822.1 son, en primer lugar, que el legatario del derecho de habitación también es heredero (legitimario), y estaríamos ante la figura del prelegado; y, en segundo lugar, que el citado legatario ya vivía en la vivienda habitual del causante de la herencia ( $\ldots$... si en el momento del fallecimiento ambos estuviesen conviviendo en ella."), es decir, ya se encontraba en posesión de la cosa sobre la que recae su derecho; $\mathrm{y}$, por tanto, estaríamos ante una excepción al principio de que el legatario ha de pedir la posesión al heredero o albacea.

Los profesores DíEz-PICAZo y GuLLóN ${ }^{8}$ recogen las siguientes excepciones al principio de que el legatario ha de pedir la posesión al heredero o albacea:

1. Cuando el propio testador haya autorizado al legatario a tomar posesión por sí del legado (Sentencia de 26 de octubre de 1.928), lo que será admisible siempre que no haya herederos forzosos. (R. de 25 de mayo de 1.971).

2. Cuando toda la herencia se ha distribuido en legados, supuesto del artículo 891 (Rs. de 30 de diciembre de 1.916 y 19 de mayo de 1.947).

3. Cuando se trate de un prelegado a favor de heredero único (Rs. de 28 de abril de 1.876 y 1 de diciembre de 1.984).

4. Cuando el legatario se encuentra en posesión de la cosa legada (Rs. de 15 de julio de 1.868 y 18 de julio de 1.900. En contra, R. de 19 de noviembre de 1.952). Sin embargo, los profesores DíEz-PICAZo y Gullón, creen que en este caso es necesaria «la entrega, única manera legal de que la posesión que ostenta el legatario se convierta en 420 .

${ }^{8}$ Sistema de Derecho Civil, volumen IV, Ed. Tecnos, Madrid, 5. ${ }^{a}$ edición, 1.989, pg. 
una posesión en concepto de dueño por la traditio aunque sea simbólica, evitándose por otra parte el peligro que representa para una hipotética acción de reducción del legado el que el legatario ya hubiese enajenado y entregado la posesión como dueño a un tercero". Sin embargo parece que éste supuesto, al que se refieren por los citados profesores, no coincide exactamente con el previsto en el artículo 822.1., ya que la posesión del legatario de ese artículo no debe convertirse - necesariamente- en posesión en concepto de dueño de la cosa (vivienda habitual del causante), además de que ese legado no se computará para el cálculo de la legítima. Por lo que, como hemos dicho antes, el supuesto previsto en el artículo 822.1 se puede considerar una excepción al principio de que el legatario ha de pedir la posesión al heredero o albacea.

\section{LEGADO DE VIVIENDA HABITUAL QUE PERTENEZCA}

\section{A LA SOCIEDAD DE GANANCIALES}

El legado de cosa ganancial se caracteriza por su gran importancia y frecuencia prácticas. Como apunta el profesor LASARTE $^{9}$ es obvio que la naturaleza y el régimen de la sociedad de gananciales conlleva que el otorgamiento del testamento, vigentes los gananciales, facilita extraordinariamente el caso de que cualquiera de los cónyuges pueda instituir legados sobre cosas que, aun siendo propias o privativas en su origen, llegado el momento de la liquidación de la sociedad de gananciales, resulten absorbidas por la presunción general de ganancialidad y/o sean atribuidas al cónyuge supérstite.

En ese sentido, se puede dar el supuesto de que una persona legue un derecho de habitación sobre su vivienda habitual que pertenezca a su sociedad de gananciales; y ello, porque el texto del artículo 1.380 del C.C. (según la reforma de la Ley 11/1.981, de 13 de mayo), permite que cualquier de los cónyuges pueda disponer por testamento de un bien ganancial pese a que antes de la partición de la sociedad ninguno tiene poder exclusivo sobre cualquiera de los bienes que forman su activo ni a ninguno le pertenece, como recogen los profesores DíEZ-PICAZo y GullóN ${ }^{10}$. Así, establece el Código Civil en el artículo 1.380 que "la disposición testamentaria de un bien ganancial

9 Principios de Derecho Civil, tomo séptimo, 3. a edición, Ed. Marcial Pons, Madrid, 2003, pág. 190.

10 Sistema de Derecho Civil, volumen IV, Ed. Tecnos, Madrid, 5. edición, 1.989, pág. 422. 
producirá todos sus efectos si fuere adjudicado a la herencia del testador». Y añade el citado artículo que " en caso contrario se entenderá legado el valor que tuviera al tiempo del fallecimiento". Esta última norma dicen los profesores Díez-PICAzo y GullóN" ${ }^{11}$ que "debe ser interpretada en el sentido de que tiene un carácter dispositivo, o si se quiere, que establece una presunción iuris tantum. La voluntad contraria del testador, por tanto, evitará su eficacia».

Por otro lado, si la vivienda habitual es adjudicada a la herencia del testador que ha legado un derecho de habitación sobre la misma, éste legado producirá todos sus efectos y estaríamos ante el supuesto previsto en el artículo 822.1. del Código Civil.

LEGADO LEGAL DE DERECHO DE HABITACIÓN SOBRE LA VIVIENDA HABITUAL

El segundo párrafo del artículo 822 del Código Civil concede al legitimario con discapacidad que lo necesite un legado legal de derecho de habitación sobre la vivienda habitual en la que conviviese con el causante, si bien a salvo de cualquier disposición testamentaria de éste sobre el derecho de habitación; en efecto, así acaba el citado párrafo: «...a menos que el testador hubiera dispuesto otra cosa o lo hubiere excluido expresamente, pero su titular no podrá impedir que continúen conviviendo los demás legitimarios mientras lo necesiten».

Este último inciso ( «....pero su titular no podrá impedir que continúen conviviendo los demás legitimarios mientras lo necesiten.») obliga al titular - por legado legal- del derecho de habitación sobre la vivienda habitual a permitir que otros legitimarios que lo necesiten convivan en la citada vivienda, lo cual es justo y razonable.

Por otro lado hay que destacar que se trata de un supuesto de legado fijado por la ley, para proteger al legitimario discapacitado que lo necesite, que se constituiría aunque el titular de la vivienda habitual no hubiese hecho testamento. Parece que estaríamos ante una excepción al principio general de que la institución del legado sólo puede llevarse a cabo mediante testamento. Por el contrario, si el titular de la vivienda habitual dejó testamento es necesario, como ya hemos dicho antes, que no "hubiera dispuesto otra cosa o lo hubiere excluido expresamente...".

${ }^{11}$ Sistema de Derecho Civil, volumen IV citado, pg. 423

(C) UNED. Revista de Derecho UNED, núm. 1, 2006 
El Código Civil en su artículo 818.1 establece que «para fijar la legítima se atenderá al valor de los bienes que quedaren a la muerte del testador, con deducción de las deudas y cargas, sin comprender entre ellas las impuestas en el testamento." Y el párrafo segundo añade que «al valor líquido de los bienes hereditarios se agregará el de las donaciones colacionables». Es decir, habrá que determinar el relictum y el donatum, y la suma de ambos conceptos arrojará el valor del haber hereditario que ha de ser tenido en cuenta a efectos de establecer las cuotas legitimarias.

Por otro lado, el Código Civil regula detalladamente (artículos 820 y 821 ) la reducción de legados y donaciones que puedan considerarse inoficiosos (legados y donaciones que superen la parte de libre disposición).

Pero hay que destacar que, por excepción, la donación y el legado previstos en el nuevo artículo 822 no computarán para la fijación de la legítima. Eso sí, para que la donación o legado de un derecho de habitación sobre la vivienda habitual no se compute para el cálculo de la legítima es necesario que el «legitimario persona con discapacidad» esté conviviendo con el titular de la vivienda —en la misma- en el momento del fallecimiento de éste.

\section{RESPETO A LOS DERECHOS DEL CONNYUGE REGULADOS EN LOS ARTÍCULOS 1.406 Y 1.407 DEL CÓDIGO CIVIL}

El párrafo cuarto del articulo 822 del Código Civil establece que lo dispuesto en los dos primeros párrafos (donación y legado de derecho de habitación sobre la vivienda habitual) "no impedirá la atribución al cónyuge de los derechos regulados en los artículos $1.406 \mathrm{y}$ 1.407 de este Código que coexistirán con el de habitación».

Los artículos citados se encuentran ubicados en la sección que el Código dedica a «la disolución y liquidación de la sociedad de ganan-

12 Los profesores DíEz-Picazo y Gullón expresan que «la figura de la adjudicación preferencial tiene por finalidad satisfacer intereses personales que podrian verse gravemente vulnerados con una participación formalmente igualitaria. Así, el interés en la continuación del ejercicio de una profesión o de una empresa, que podría verse impedido si los bienes dedicados a este objeto se partieran, o el interés en mantener o preservar la vivienda y los bienes de uso personal»; en Sistema de Derecho Civil, volumen IV, Ed. Tecnos, Madrid, 5. . edición, 1.989, pg. 421. 
ciales» y otorgan a cada uno de los cónyuges el derecho de atribución o adjudicación preferente en relación a un conjunto de bienes gananciales ${ }^{12}$, aunque no quepan matemáticamente hablando en su lote respectivo y, por tanto, generen las correspondientes compensaciones en metálico.

Así, establece el artículo 1.406 que «cada cónyuge tendrá derecho a que se incluyan en su haber, hasta donde éste alcance:

$1^{\circ}$. Los bienes de uso personal no incluidos en el número $7 \mathrm{del}$ artículo 1.346. $2^{\circ}$. La explotación económica que gestione efectivamente.

$3^{\circ}$. El local donde hubiese venido ejerciendo su profesión.

$4^{\circ}$. En caso de muerte del otro cónyuge, la vivienda donde tuviese la residencia habitual».

Sin embargo, a continuación, el Código contradice el inciso inicial del artículo 1.406 ( «cada cónyuge tendrá derecho a que se incluyan en su haber, hasta donde éste alcance») en relación al local destinado al ejercicio de la profesión y a la vivienda habitual, pues el artículo 1.407 dispone que «en los casos de los números 3 y 4 del artículo anterior podrá el cónyuge pedir, a su elección, que se le atribuyan los bienes en propiedad o que se constituya sobre ellos a su favor un derecho de uso o habitación. Si el valor de los bienes o el derecho superara al del haber del cónyuge adjudicatario deberá éste abonar la diferencia en dinero». El cónyuge, por tanto, mantiene su derecho de adjudicación preferente - respecto del local donde hubiese venido ejerciendo su profesión y respecto de su vivienda habitual- aunque el valor de esos bienes o, en su caso, el de los derechos de uso o habitación, supere el importe de su haber; simplemente tendrá que compensar en metálico la diferencia.

Como sabemos, lo dispuesto en el artículo 822 afecta básicamente a la vivienda habitual del causante de la herencia y, en su caso, de su cónyuge. Si éste último solicita que sobre la citada vivienda se constituya a su favor un derecho de uso o de habitación, dicho derecho podrá coexistir con el derecho de habitación del legitimario discapacitado (artículo 822.4). Si, por el contrario, el cónyuge supérstite solicita que se le atribuya en propiedad la vivienda habitual - aunque tenga que compensar alguna cantidad en metálico- habría que aplicar el artículo 1.380 del Código Civil ( ....se entenderá legado el valor que tuviera al tiempo del fallecimiento».) De todas formas, si el legitimario discapacitado al que se le legó el derecho de habitación es también hijo del cónyuge supérstite - que se atribuye 
en propiedad la vivienda habitual - lo normal es que dicho legitimario discapacitado pueda habitar la citada vivienda (aunque no tenga derecho de habitación) junto con dicho cónyuge (sería el caso de una madre que se atribuye en propiedad la vivienda habitual - por muerte de su cónyuge- - y sigue viviendo en ella con su hijo discapacitado). La cuestión se puede plantear más problemática si el legitimario discapacitado al que se legó el derecho de habitación fuese ascendiente del causante de la herencia y el cónyuge supérstite no quisiese que habitase la vivienda habitual. En este caso parece que tendría que conformarse sólo con el valor del derecho de habitación que le legó el causante de la herencia (artículo 1.380). 